\title{
Comparison of NLC particle sizes derived from SCIAMACHY/Envisat observations with ground-based LIDAR measurements at ALOMAR $\left(69^{\circ} \mathrm{N}\right)$
}

\author{
C. von Savigny ${ }^{1}$, C. E. Robert ${ }^{1}$, G. Baumgarten ${ }^{2}$, H. Bovensmann ${ }^{1}$, and J. P. Burrows ${ }^{1}$ \\ ${ }^{1}$ Institute of Environmental Physics and Remote Sensing, University of Bremen, Otto-Hahn-Allee 1, 28359 Bremen, Germany \\ ${ }^{2}$ Institute of Atmospheric Physics, Schlossstr. 6, 18225 Kühlungsborn, Germany
}

Received: 9 April 2009 - Published in Atmos. Meas. Tech. Discuss.: 27 April 2009

Revised: 23 Aug 2009 - Accepted: 2 September 2009 - Published: 18 September 2009

\begin{abstract}
SCIAMACHY, the Scanning Imaging Absorption spectroMeter for Atmospheric CHartographY has provided measurements of limb-scattered solar radiation in the $220 \mathrm{~nm}$ to $2380 \mathrm{~nm}$ wavelength range since summer of 2002 . Measurements in the UV spectral range are well suited for the retrieval of particle sizes of noctilucent clouds (NLCs) and have been used to compile the largest existing satellite data base of NLC particle sizes. This paper presents a comparison of SCIAMACHY NLC size retrievals with the extensive NLC particle size data set based on ground-based LIDAR measurements at the Arctic LIDAR Observatory for Middle Atmosphere Research (ALOMAR, $69^{\circ} \mathrm{N}, 16^{\circ} \mathrm{E}$ ) for the Northern Hemisphere NLC seasons 2003 to 2007. Most of the presented SCIAMACHY NLC particle size retrievals are based on cylindrical particles and a Gaussian particle size distribution with a fixed width of $24 \mathrm{~nm}$. If the differences in spatial as well as vertical resolution between SCIAMACHY and the ALOMAR LIDAR are taken into account, very good agreement is found. The mean particle size derived from SCIAMACHY limb observations for the ALOMAR overpasses in 2003 to 2007 is $56.2 \mathrm{~nm}$ with a standard deviation of $12.5 \mathrm{~nm}$, and the LIDAR observations yield a value of $54.2 \mathrm{~nm}$ with a standard deviation of $17.4 \mathrm{~nm}$.
\end{abstract}

\section{Introduction}

Noctilucent clouds (NLCs) - which are also known as polar mesospheric clouds (PMCs) - are a summertime high latitude phenomenon occurring at altitudes of about $83-85 \mathrm{~km}$. The NLC particles mainly consist of $\mathrm{H}_{2} \mathrm{O}$ ice (Hervig et al., 2001) and the particle sizes reach values of several tens of

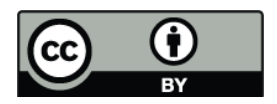

Correspondence to: C. von Savigny (csavigny@iup.physik.uni-bremen.de) nanometers (e.g., von Savigny and Burrows, 2007; Baumgarten et al., 2008). Although the scientific understanding of many NLC characteristics has improved in recent years, several important aspects are only poorly understood or not understood at all. For example, the shape of the NLC particles is not fully established (e.g., Baumgarten et al., 2002; Eremenko et al., 2005; Hervig et al., 2009), there is still debate on the correct NLC particle size distribution, and the generally accepted particle formation mechanism - heterogeneous nucleation on meteoric smoke particles - has recently been questioned (e.g., Megner et al., 2008).

NLC particle sizes are derived from the ground using multi-color LIDAR systems (e.g., von Cossart et al., 1999; Baumgarten et al., 2008), from rockets using photometers - exploiting both the spectral dependence of the NLC scattering cross section as well as the scattering phase function (e.g., Gumbel and Witt, 2001) - and from satellites using spectroscopic observations. Most of the existing satellite observations of NLC particle sizes rely on observing the spectral dependence of scattering or extinction by NLC particles in limb-scatter (e.g., Rusch et al., 1991; Karlsson and Rapp, 2006; Robert et al., 2009) or occultation (e.g., Debrestian et al., 1997; Lumpe et al., 2008) geometry, but particle size retrievals based on phase function measurements were also made using limb-scatter (e.g., Thomas and McKay, 1985; Rusch et al., 2008) and nadir observations (Bailey et al., 2009). Most of the recently published NLC particle size observations are in good agreement (see, e.g., Fig. 6 in von Savigny and Burrows, 2007), with the exception of Carbary et al. (2004), who presented indications for a bi-modal NLC particle size distribution based on UVISI/MSX satellite observations with a large mode at radii exceeding $200 \mathrm{~nm}$. The studies by DeLand et al. (2005) and von Savigny et al. (2007) contradict the hypothesis of a large particle mode near $200 \mathrm{~nm}$, and are consistent with a mono-modal particle size distribution with sizes of several tens of nanometers.

Published by Copernicus Publications on behalf of the European Geosciences Union. 
In most of these previously published studies on NLC particle sizes the retrieved radii were only qualitatively compared to independent measurements often made at different locations in different seasons, different parts of the solar cycle, even different solar cycles, and local times. In this study we attempt for the first time the comparison of NLC particle radii measured from space - with the SCIAMACHY (Scanning Imaging Absorption spectroMeter for Atmospheric CHartographY) instrument on the Envisat spacecraft - with spatially co-located ground-based observations made with the ALOMAR RMR (Rayleigh-MieRaman) LIDAR. A comprehensive validation of the SCIAMACHY NLC particle sizes is difficult, due to the large spatial and temporal variability observed in NLCs (e.g., Baumgarten et al., 2009) and the large differences in the sampled air volumes between SCIAMACHY and the ALOMAR LIDAR.

\section{Instrumentation}

\subsection{SCIAMACHY on Envisat}

SCIAMACHY (Bovensmann et al., 1999) is one of ten scientific instruments aboard the European Space Agency's Envisat spacecraft. Envisat was launched on 1 March 2002 from Kourou (French Guiana) into a polar, sun-synchronous orbit with a 10:00 LST (local solar time) descending node. SCIAMACHY measures solar radiation scattered by and transmitted through the atmosphere in nadir, solar/lunar occultation and limb-scatter mode. For this study only limb-scatter observations - fully calibrated Level 1 data with Level-0-to-1 processor version 6.03 - are employed. In limb observation mode SCIAMACHY scans the Earth's limb from the surface up to about $92 \mathrm{~km}$ in steps of $3.3 \mathrm{~km}$ for the data used here. The geometrical field of view (FOV) is about $2.8 \mathrm{~km}$ in the vertical direction and about $110 \mathrm{~km}$ in the horizontal direction. Azimuthal scanning at every tangent height leads to an effective spatial smearing over a distance of $960 \mathrm{~km}$ perpendicular to the viewing direction. In viewing direction the spatial smearing corresponds to about $400 \mathrm{~km}$.

\subsection{The ALOMAR RMR LIDAR}

NLC particle properties are retrieved from active remote sensing measurements with the ALOMAR RMR-LIDAR in Northern Norway $\left(69^{\circ} \mathrm{N}, 16^{\circ} \mathrm{E}\right)$. Throughout the NLC season (1 June to 15 August) the LIDAR is operated $24 \mathrm{~h}$ per day to measure whenever weather permits. The LIDAR emits laser pulses at three widely separated wavelengths $(355 \mathrm{~nm}$, $532 \mathrm{~nm}, 1064 \mathrm{~nm}$ ). The laserpulses are scattered back by air molecules and particles in the atmosphere and are collected by telescopes with a diameter of $1.8 \mathrm{~m}$. The light received is recorded by single photon counting detectors. After separation of particle and molecular signal, the particle properties are calculated by comparison to modelled optical parti- cle signals. Here we use the vertically resolved NLC particle size retrievals described by Baumgarten and Fiedler (2008), that provide particle size information for up to three independent layers. The center layer is characterized by backscatter signals $\beta_{532 \mathrm{~nm}}$ exceeding $0.7 \times \beta_{\max }$, where $\beta_{\max }$ is the maximum of the observed NLC backscatter signal at $532 \mathrm{~nm}$. Furthermore, particle sizes are retrieved above and below the center layer including altitudes were the measurement signal is greater than two times the measurement uncertainty. Further information on the NLC particle size retrievals from the ALOMAR RMR-LIDAR can also be found in Baumgarten et al. (2008).

\section{NLC particle size retrievals from SCIAMACHY limb observations}

A detailed description of the method to retrieve NLC particle sizes from SCIAMACHY limb-scatter observations in the UV spectral range was recently given by Robert et al. (2009). Therefore, only the most important aspects will be briefly discussed here. NLC scattering spectra are extracted for the tangent height with the maximum NLC radiance, which has a mean value of $82.2 \mathrm{~km}$ for the SCIAMACHY limb measurements considered in this comparison. The NLC Angstrøm exponents are determined from NLC scattering spectra in the 265-300 nm spectral range. The NLC particle sizes are then retrieved from these Ångstrøm exponents using look-up tables determined with a T-matrix method (Mishchenko and Travis, 1998) for specific particle shapes and size distributions. Unlike the ALOMAR RMR LIDAR measurements, the SCIAMACHY limb observations do not allow the retrieval of 2 size distribution parameters. Therefore, the width of a normal or log-normal particle size distribution has to be assumed, and then the mean or mode radius can be retrieved. For most results presented here a Gaussian size distribution was used

$f(r)=\frac{1}{\sqrt{2 \pi} \sigma} e^{-\left(r-r_{0}\right)^{2} /\left(2 \sigma^{2}\right)}$

with $r_{0}$ being the mean radius, and $\sigma$ being the width of the size distribution.

Furthermore, cylindrical NLC particles were assumed, and particle size retrievals were performed for the following aspect ratios: $0.2,0.5,1,2$, and 5 . The aspect ratio is 1 if not stated otherwise. The LIDAR observations presented by Baumgarten et al. (2007) (their Table 2) indicated that for cylindrical particle shape and a Gaussian particle size distribution the fraction of observed color ratios that was compatible with modelled color ratios was larger than for spheres and spheroids. Cylindrical particles are also assumed for the NLC particle sizes derived from the LIDAR observations used in this study. 
The width of the particle size distribution employed for the size retrievals from SCIAMACHY measurements was chosen based on the following considerations: the LIDAR observations by Baumgarten et al. (2008) resulted in a width of $\sigma_{\text {LIDAR }} \approx 17 \mathrm{~nm}$. However, the horizontal area (at NLC altitude) sampled for individual particle size measurements is typically about $20 \mathrm{~m} \times 30 \mathrm{~km}$ for the LIDAR measurements (for an integration time of $14 \mathrm{~min}$ ), hence significantly smaller than for the SCIAMACHY observations, i.e., about $1000 \mathrm{~km} \times 400 \mathrm{~km}$. In order to take the variability of the mean NLC radii within the air volume sampled by SCIAMACHY into account, we use as width $\left(\sigma_{\text {SCIA }}\right)$ of the assumed Gaussian particle size distribution the square root of the sum of $\sigma_{\text {LIDAR }}^{2}$ and the squared standard deviation of the mean radii observed by the LIDAR $(\sigma \approx 17 \mathrm{~nm})$ :

$\sigma_{\mathrm{SCIA}}=\sqrt{\sigma_{\mathrm{LIDAR}}^{2}+\sigma^{2}} \approx 24 \mathrm{~nm}$

In other words, we can imagine the air volume sampled by SCIAMACHY to be composed of the much smaller air volumes sampled by the LIDAR for which the width of the size distribution is $\sigma_{\mathrm{LIDAR}}=17 \mathrm{~nm}$, and the standard deviation of the mean sizes is also $\sigma=17 \mathrm{~nm}$. In order to back up this approach numerically, we performed Monte-Carlo simulations, where we superimposed normally distributed random variables with $17 \mathrm{~nm}$ width and with mean sizes which are also normally distributed with $17 \mathrm{~nm}$ width. Using this approach the effective width in Eq. (2) can be confirmed with arbitrary accuracy, if the ensemble size is chosen large enough.

Finally, we note that the SCIAMACHY limb spectra in the spectral range used for the NLC particle size retrieval are affected by a spectrally non-uniform degradation. The instrumental throughput for all SCIAMACHY channels is monitored on a daily basis and daily instrumental transmission spectra (without atmospheric absorption signatures) are determined by the SCIAMACHY Operations Support Team (SOST) and provided via internet (http://www.iup.physik.uni-bremen.de/sciamachy/LTM/ LTM_spectral/LTM_spectral.html). These transmission spectra are employed to determine the spectral exponent of the instrumental degradation, which is applied as a correction to the derived NLC Ångstrøm exponent. A detailed description of the approach can be found in Robert et al. (2009).

\section{Comparisons}

We note again, that all SCIAMACHY NLC particle size retrievals shown in Figs. 3-6 are based on cylindrical particles, and a Gaussian particle size distribution of width $24 \mathrm{~nm}$.

\subsection{Subset selection}

For the comparison with the LIDAR observations above ALOMAR only SCIAMACHY limb observations made during the descending part (pole to equator) of the Envisat orbit were used. This restriction was imposed, because the scattering angles of the ascending part observations are relatively small $\left(23^{\circ}-27^{\circ}\right)$ at a latitude of $69^{\circ} \mathrm{N}$ and for these scattering angles the expected Ångstrøm exponents are only weakly dependent on the mean particle radius (see Fig. 1). As Fig. 1 illustrates, the Ångstrøm exponent for the ascending part observations will only change by 0.5 when increasing the mean radius from 20 to $70 \mathrm{~nm}$. For the descending part observations this radius change will lead to a difference in Angstrom exponent of 1.5. This implies that the retrieval for the ascending part observations is less sensitive to NLC particle size than for the descending part of the orbit, where scattering angles are typically $47^{\circ}-55^{\circ}$ at $69^{\circ} \mathrm{N}$ latitude.

The following coincidence criteria were chosen: The center point of the SCIAMACHY limb ground swath has to be within $-4^{\circ} /+3^{\circ}$ in terms of latitude and $\pm 16^{\circ}$ in terms of longitude of the geolocation of ALOMAR $\left(69^{\circ} \mathrm{N}, 16^{\circ} \mathrm{E}\right)$. The asymmetrical latitudinal criterion was chosen in order to ensure that the mean latitude of the SCIAMACHY observations corresponds to the latitude of the LIDAR site (there are more SCIAMACHY particle size retrievals at higher latitudes). Figure 2 shows the locations of the SCIAMACHY ground swath center points of all co-locations used in this comparison, together with an example of a SCIAMACHY limb ground swath.

\subsection{Altitude weighting}

SCIAMACHY's vertical field of view corresponds to about $2.8 \mathrm{~km}$ at the tangent point, whereas the LIDAR observations allowed the retrieval of the vertical variation of particle sizes within the NLC. As described in Baumgarten and Fiedler (2008) NLC particle sizes were retrieved below, at and above the NLC brightness peak with the mean altitudes of the corresponding layers being $81.7 \mathrm{~km}, 82.6 \mathrm{~km}$, and $83.3 \mathrm{~km}$ (see Table 1 in Baumgarten and Fiedler, 2008). SCIAMACHY is not capable of resolving the vertical variation of particle sizes within the NLC. Figure 3 shows the comparison of annually averaged SCIAMACHY size retrievals above ALOMAR with the LIDAR observations at (left panel) and below (right panel) the NLC brightness peak. The SCIAMACHY radii are on average about $9 \mathrm{~nm}$ larger than the LIDAR radii at the peak, and about $7 \mathrm{~nm}$ smaller than the LIDAR radii below the peak.

Because of the different vertical resolutions of SCIAMACHY and the LIDAR the comparison of the SCIAMACHY retrievals with either the LIDAR values at the peak or below the peak only is not appropriate. Therefore, a weighted average of the vertically varying sizes derived from the LIDAR observations was determined prior to comparison 


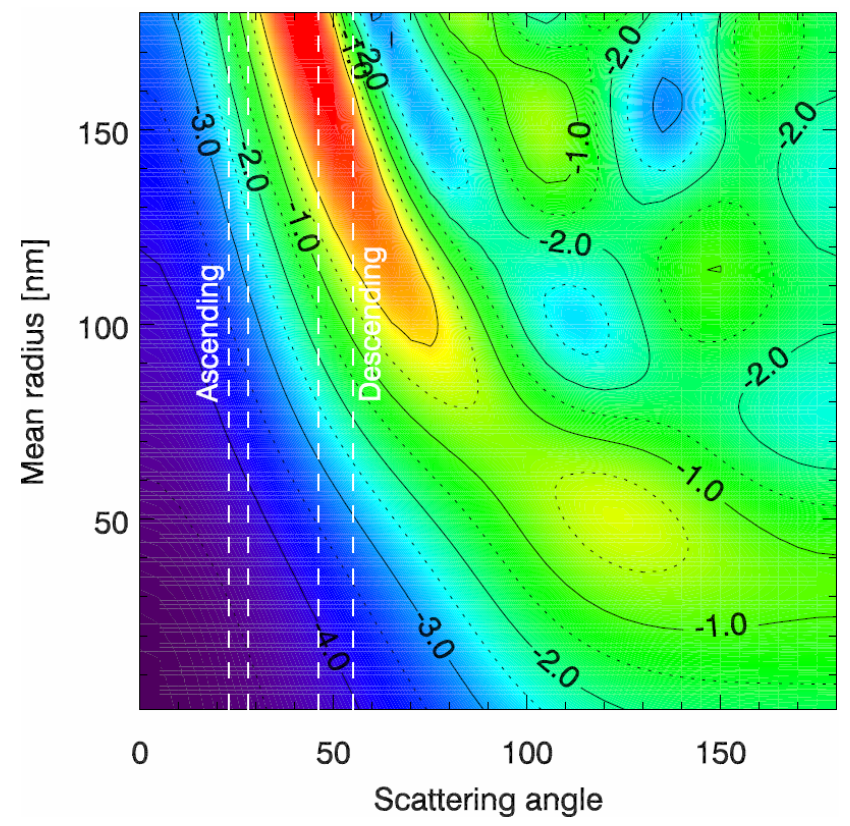

Fig. 1. Angstrøm exponent in the $265 \mathrm{~nm}$ to $300 \mathrm{~nm}$ spectral window for a Gaussian particle size distribution with $\sigma=24 \mathrm{~nm}$, cylindrical particles with an aspect ratio of $\epsilon=1.0$ as a function of scattering angle and mean radius. The white dashed lines indicate the scattering angles of SCIAMACHY limb observations above ALOMAR $\left(69^{\circ} \mathrm{N}\right)$ for the ascending and descending parts of the orbit. The scattering angles for Southern Hemisphere observations at polar latitudes are about $130^{\circ}-160^{\circ}$.

\section{Geolocation of co-located SCIAMACHY observations}

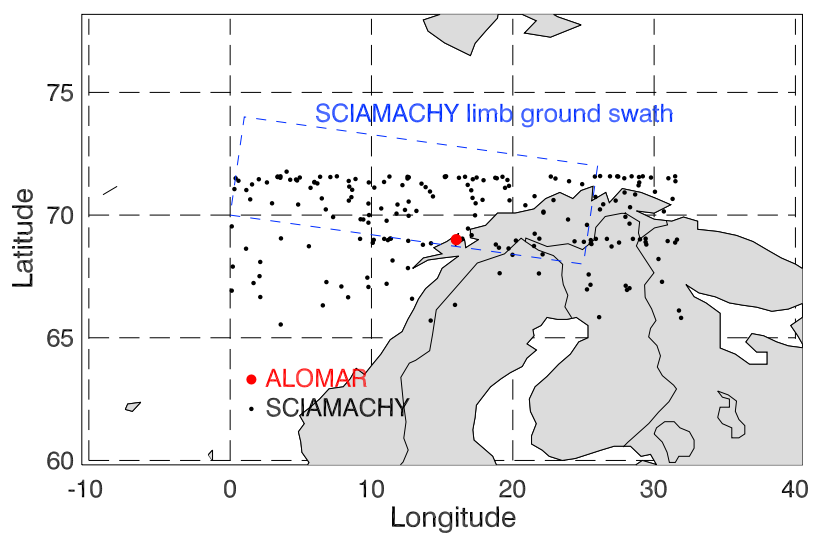

Fig. 2. Illustration of the size of the SCIAMACHY limb groundswath (blue dashed line). Also shown are the geolocations of the ground swath center points (black dots) of all SCIAMACHY observations used in this comparison, and of the ALOMAR observatory (solid red circle).

with the SCIAMACHY retrievals. The weighting factors $w_{l}$, $w_{p}$, and $w_{u}$ (l=lower, $\mathrm{p}=$ peak, $\mathrm{u}=$ upper) for the three layers as observed by the LIDAR were modelled in order to represent the contributions of each layer to the total observed limb signal, i.e., they were assumed to be proportional to the mean NLC particle number density $\left(n_{l}, n_{p}, n_{u}\right.$ as taken from Table 1 in Baumgarten and Fiedler, 2008) and the 5th power of the mean radius for each of the three layers.

$w_{i}=n_{i} \times r_{i}^{\alpha}, \quad i \in\{u, p, l\}$

$\alpha=5.0$ was used here, because Mie-simulations showed that for particle radii of $30-60 \mathrm{~nm}$, the differential scattering cross sections do not follow the $\propto r^{6}$ scaling expected for the Rayleigh regime, but scale with exponents between about 4.5 and 5.5. Below we will also test the sensitivity of the derived weighted averages to the assumed scaling exponent (see Sect. 5).

The vertically weighted average radius derived from the LIDAR observations is then given by:

$\bar{r}_{\text {LIDAR }}=\frac{w_{l} r_{l}+w_{p} r_{p}+w_{u} r_{u}}{w_{l}+w_{p}+w_{u}}$

Due to the limited number of direct co-locations between SCIAMACHY and the LIDAR observations (i.e., spatially co-located observations made on the same day), we start comparing mean particle sizes averaged over the individual NLC seasons 2003 to 2007. Figure 4 shows the comparison of annually averaged NLC radii retrieved with SCIAMACHY for the geolocation criteria mentioned above and the vertically weighted LIDAR observations derived from Eq. (4) for the Northern Hemisphere NLC seasons 2003 to 2007. The NLC particle sizes for the individual years are also presented in Table 1. The mean difference (SCIAMACHY - LIDAR) for all years is only $2.0 \mathrm{~nm}$. If 2007 - which shows the largest differences between SCIAMACHY and the weighted LIDAR radii - is omitted, then the mean difference is only $-0.7 \mathrm{~nm}$. The reason for the larger difference in 2007 is not yet established. It must be pointed out that the LIDAR NLC size retrievals shown in Figs. 3 and 4 correspond to observations made at all local times. However, the SCIAMACHY limb observations at $69^{\circ} \mathrm{N}$ during the descending part of the orbit are all made at a constant local time of about 11:30, because of the Envisat orbit being sunsynchronous. If we restrict the times of the LIDAR observations to the time of the SCIAMACHY overpass $\pm 2.5 \mathrm{~h}$, then a value of $\bar{r}_{\text {LIDAR }}=53.0 \mathrm{~nm}$ for the vertically weighted particle size is obtained. This is only slightly smaller than the value of $\bar{r}_{\text {LIDAR }}=54.2 \mathrm{~nm}$ obtained without local time restriction. Note that the number of co-locations for these restricted temporal conditions is rather limited. This is partly caused by the local time dependence of NLC occurrence which shows reduced NLC occurrence around 11:00 local time (Fiedler et al., 2005).

\section{Discussion}

The altitude weighting of the LIDAR NLC particle sizes described in Sect. 4.2 relied on the assumption of the dependence of the NLC scattering cross section on particle size. 

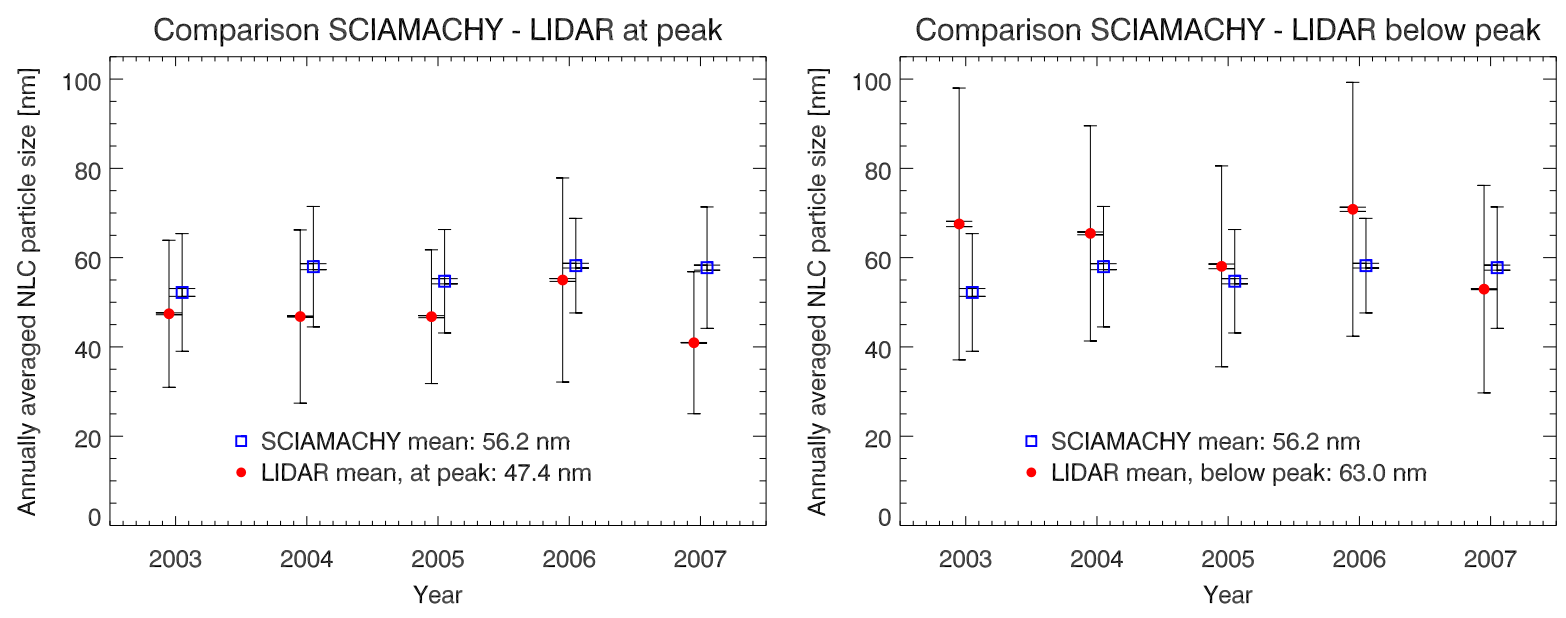

Fig. 3. Comparison of annually averaged SCIAMACHY NLC particle sizes observed above ALOMAR with the LIDAR measurements of NLC particle sizes at the NLC brightness peak (left panel) and below the brightness peak (right panel). The retrievals are based on a normal particle size distribution with $\sigma=24 \mathrm{~nm}$ and cylindrical particles with an aspect ratio of $\epsilon=1.0$, and only descending leg observations are employed. The large error bars show the standard deviations about the annual mean values, and the small error bars correspond to the errors of the mean.

Table 1. SCIAMACHY and LIDAR NLC particle size retrievals. Shown are the annual mean vertically weighted LIDAR and the SCIAMACHY NLC particle sizes, the standard deviation about the annual mean values and the total number of observations per year for the Northern Hemisphere NLC seasons 2003-2007 above ALOMAR.

\begin{tabular}{ccccccc}
\hline Year & \multicolumn{3}{c}{ LIDAR } & \multicolumn{3}{c}{ SCIAMACHY } \\
& Annual mean & Std. dev. & \# obs. & Annual mean & Std. dev. & \# obs. \\
\hline 2003 & $57.6 \mathrm{~nm}$ & $19.6 \mathrm{~nm}$ & 51 & $52.2 \mathrm{~nm}$ & $13.1 \mathrm{~nm}$ & 15 \\
2004 & $57.2 \mathrm{~nm}$ & $18.7 \mathrm{~nm}$ & 77 & $58.0 \mathrm{~nm}$ & $13.5 \mathrm{~nm}$ & 20 \\
2005 & $51.6 \mathrm{~nm}$ & $15.7 \mathrm{~nm}$ & 43 & $54.7 \mathrm{~nm}$ & $11.6 \mathrm{~nm}$ & 20 \\
2006 & $59.5 \mathrm{~nm}$ & $19.6 \mathrm{~nm}$ & 60 & $58.2 \mathrm{~nm}$ & $10.6 \mathrm{~nm}$ & 20 \\
2007 & $45.3 \mathrm{~nm}$ & $13.5 \mathrm{~nm}$ & 182 & $57.7 \mathrm{~nm}$ & $13.6 \mathrm{~nm}$ & 24 \\
Total & $54.2 \mathrm{~nm}$ & $17.4 \mathrm{~nm}$ & 413 & $56.2 \mathrm{~nm}$ & $12.5 \mathrm{~nm}$ & 99 \\
\hline
\end{tabular}

We assumed that the scattering cross section scales with the 5th power of NLC particle radius. This choice appears reasonable, but it is somewhat arbitrary. Therefore, we briefly discuss the effect of changing the exponent on the inferred vertically weighted LIDAR particle sizes. The exponent was increased from 3.0 to 6.0 in steps of 0.5 and the effect on the derived vertically weighted LIDAR particle sizes is shown in Fig. 5, both averaged over all local times, and for local times between 09:00 and 14:00 only (LT of SCIAMACHY overpass $\pm 2.5 \mathrm{~h}$ ). Apparently, the dependence of vertically weighted particle sizes on the assumed exponent is relatively small, changing by less than $1 \mathrm{~nm}$ if the exponent is changed by 1.0. We therefore conclude that the effect of a variable $\alpha$ on the weighted LIDAR particle sizes is much smaller than the standard deviation of the observations, and can be neglected.

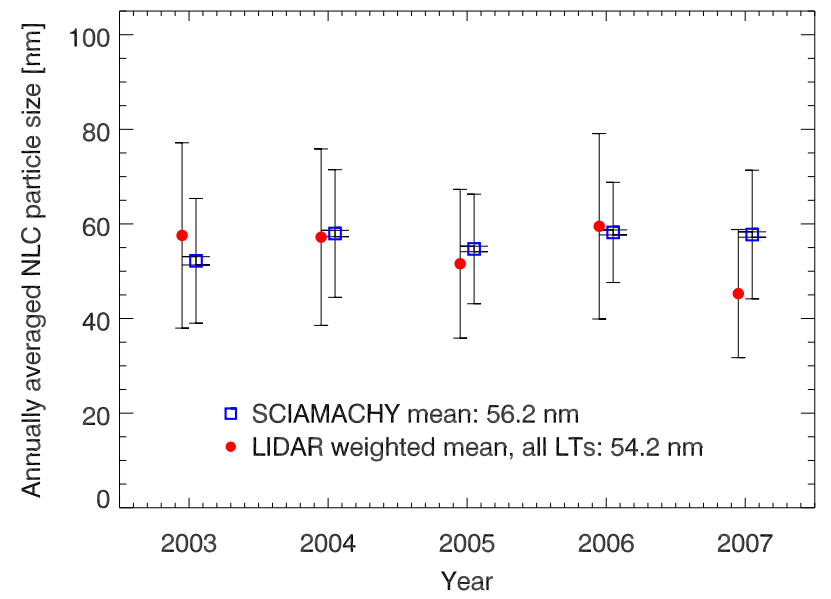

Fig. 4. Comparison of annual mean SCIAMACHY NLC particle sizes above ALOMAR with the weighted LIDAR particle sizes calculated using Eq. (4). The large error bars correspond to the standard deviations.

The SCIAMACHY and LIDAR NLC sizes compared above were seasonally averaged values co-located in the spatial domain, but the observations were not necessarily performed on the same days during the NLC seasons. In Fig. 6 we show comparisons only for spatially co-located observations made on the same day. Note that unfortunately no local time restriction of the LIDAR observations is possible, because of the small number of coincidences. The number of co-located observations on the same day is quite limited for the following reasons: (a) about $60 \%$ of the LIDAR observations are affected by tropospheric clouds, making a particle 


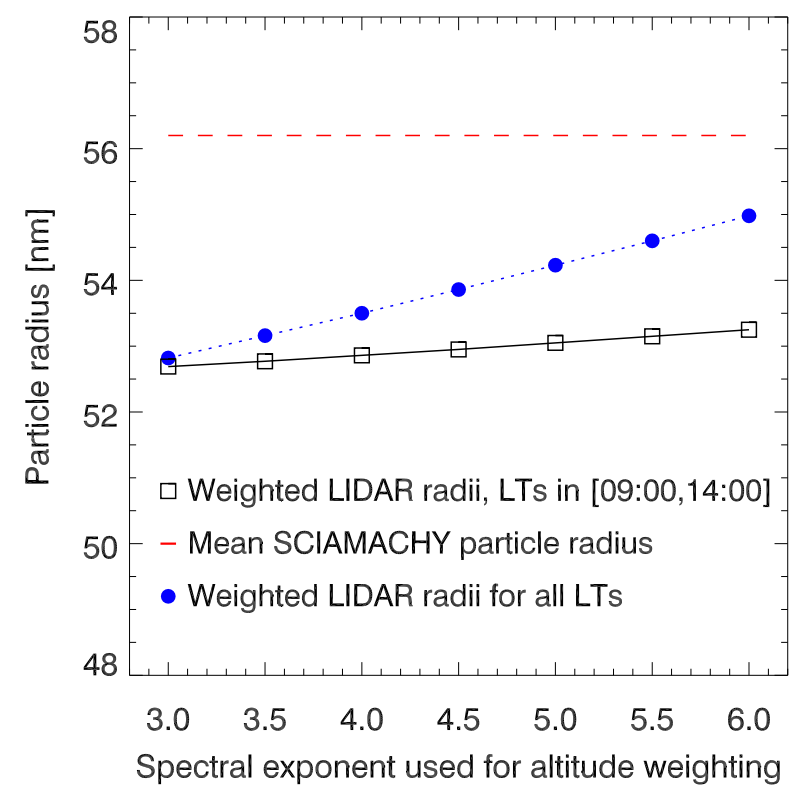

Fig. 5. Dependence of the vertically weighted LIDAR NLC radii on exponent $\alpha$ (Eq. 3). The red dashed line shows the SCIAMACHY NLC particle sizes averaged over all years, which are of course independent of $\alpha$.

size retrieval impossible; (b) although the LIDAR is operated continuously, only 1 in 5 ( 1 in 10 before 2005) observations is a multi-color observations allowing to retrieve particle size; (c) SCIAMACHY particle size retrievals are not available for each day during the season due to measurement interruptions or NLC signatures being to weak for particle size retrievals (see Robert et al., 2009). The left panel in Fig. 6 shows a comparison without altitude weighting of the LIDAR observations, and the particle sizes retrieved below, at, and above the brightness peak are shown separately. The error bars of the SCIAMACHY NLC particle sizes are the error estimates for individual size retrievals (see Robert et al. (2009) for more details). The LIDAR sizes for the different altitudes are averages over all LIDAR observations available for any given day on which co-locations exist, and the error bars on the LIDAR sizes correspond to the standard deviation of these multiple measurements per day. Note that LIDAR measurements are not always available at all three altitudes for days with co-locations. This could for example be caused by narrow cloud layers with large vertical gradients at cloud top or bottom, or by weak signals due to weak NLCs or possibly large variability on temporal scales smaller than the integration time of $14 \mathrm{~min}$. The larger scatter of the LIDAR NLC particle radii in the left panel of Fig. 6 is partly due to the fact, that the three altitude regimes are shown separately, in combination with the known vertical variation of particle size within the cloud. Another likely reason for the larger scatter of the LIDAR particle sizes is the small size of the air volume sensed - compared to SCIAMACHY - together with the variability of NLCs on small scales.
In a next step, only those observations are used for which measurements at all three altitudes were available, and the LIDAR retrievals were altitude averaged as described in Sect. 4.2. A comparison with the SCIAMACHY particle sizes is shown in the right panel of Fig. 6. The average SCIAMACHY size for these 15 co-locations is $57.5 \mathrm{~nm}$, and the average LIDAR particle size is about $7 \mathrm{~nm}$ larger. This agreement is slightly worse than for the comparison presented in Sect. 4.2, which was based on a much larger sample, because the condition, that SCIAMACHY and LIDAR observations were made on the same days during the NLC seasons, was not imposed. The larger differences in Fig. 6 may be due to the fact that differences caused by the markedly different sizes of the sampled air volumes become smaller if a larger number of measurements is considered.

Both panels of Fig. 6 show a bifurcation in the SCIAMACHY NLC particle sizes with values in the intervals [35 nm, $50 \mathrm{~nm}]$ and $[60 \mathrm{~nm}, 70 \mathrm{~nm}]$ and none in between. This bifurcation is likely caused by the small number of direct collocations, because it disappears if the size retrievals for all ALOMAR overpasses are considered. We attribute the relatively large range of LIDAR particle sizes to the intrinsic variability of NLC particle sizes in combination with the small (compared to SCIAMACHY) horizontal scales sampled by individual LIDAR observations $(20 \mathrm{~m} \times 30 \mathrm{~km})$.

Previously published NLC particle size retrievals were often based on spherical particles and a log-normal particle size distribution. Therefore, we briefly discuss the dependence of the SCIAMACHY NLC particle size retrievals (over ALOMAR) on the assumed particle size distribution and particle shape for a few selected cases (see Table 2). A comprehensive compilation of the dependence of NLC particle sizes on all possible combinations of particle shape, particle size distribution, distribution width, and aspect ratio is beyond the scope of this study. We first note that the mean particle size for spherical particles with a Gaussian particle size distribution and $\sigma=24 \mathrm{~nm}$ differs by less than $1 \mathrm{~nm}$ from the particle sizes for cylindrical particles with the same distribution type and width. For a log-normal particle size distribution with $\sigma=1.4$ - often used in previous publications - the mean particle size is slightly smaller (about $51 \mathrm{~nm}$ on average). Finally, if the aspect ratio $\epsilon$ for cylindrical particles is set to 0.5 or 2.0 , the mean particle sizes change by up to $6 \mathrm{~nm}$ from the standard case with an aspect ratio of 1.0. Setting $\epsilon$ to 0.2 leads to significantly larger particles sizes (about $78 \mathrm{~nm}$ on average).

It must also be mentioned that the retrieved mean radii strongly depend on the assumed width of the particle size distribution. As outlined above, we assumed $\sigma_{\text {SCIA }}=24 \mathrm{~nm}-$ in order to take the very different sizes of the air volumes sampled by SCIAMACHY and the LIDAR into account. If we assume the width of the normal particle size distribution to be identical to the value retrieved from the LIDAR observations $(\sigma=17 \mathrm{~nm})$, then the mean SCIAMACHY particle size averaged over all ALOMAR co-locations for the 

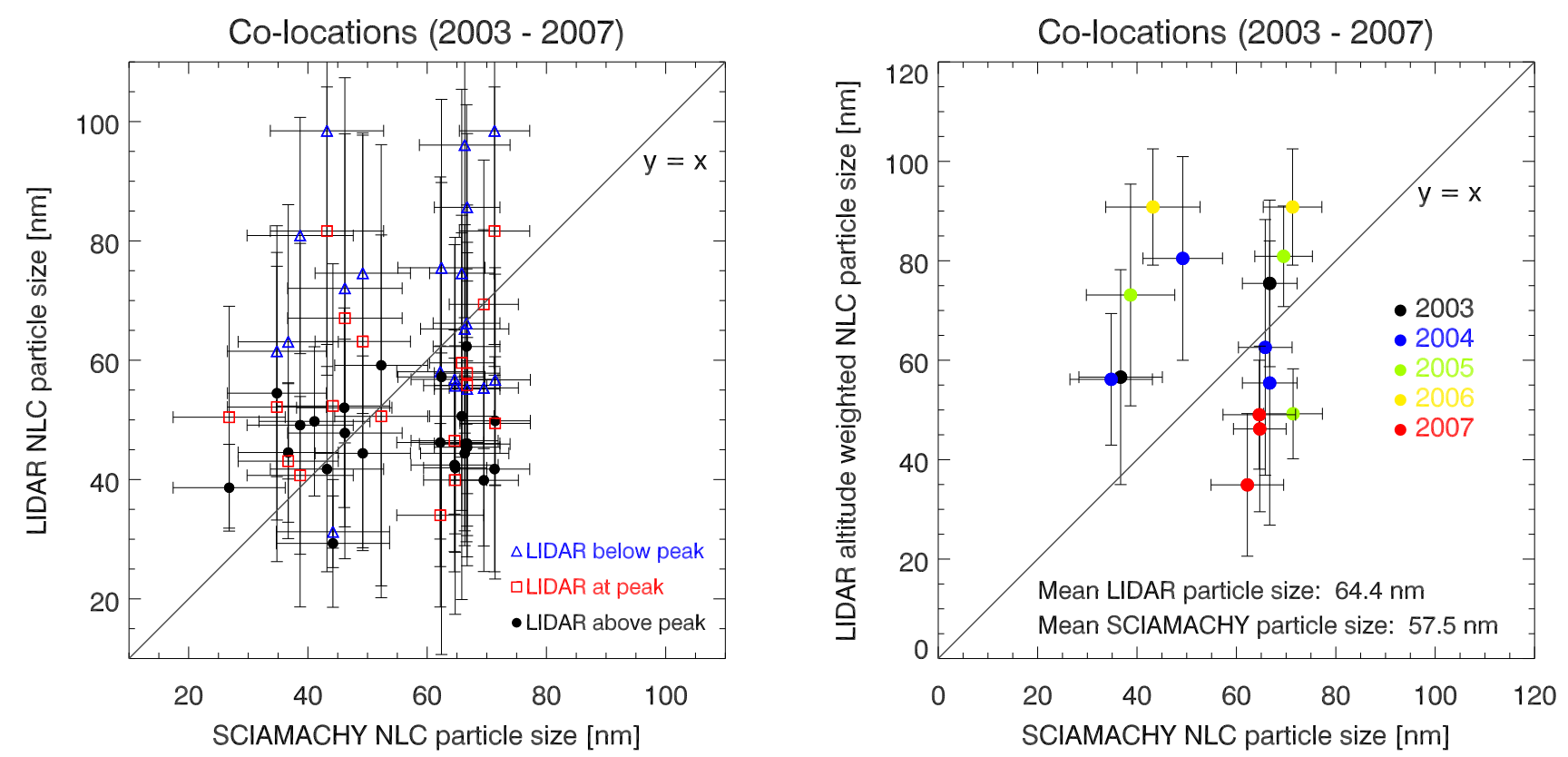

Fig. 6. Comparison of SCIAMACHY and LIDAR NLC particle sizes for spatially co-located observations made on the same day. Left panel: the LIDAR observations above the brightness peak, at, and below the peak are shown separately. Right panel: only LIDAR observations are used for which NLC particle sizes below, at, and above the brightness peak are available; the LIDAR sizes were vertically weighted according to Eq. (4) and the weighting factors in Eq. (3) were determined with $\alpha=5.0$.

Table 2. Averaged SCIAMACHY NLC particle sizes for all ALOMAR overpasses 2003-2007 for different aspect ratios of the cylindrical particles, and for spherical particles with a normal and lognormal particle size distribution.

\begin{tabular}{cccc}
\hline $\begin{array}{c}\text { Particle size } \\
\text { distribution }\end{array}$ & $\begin{array}{c}\text { Particle } \\
\text { shape }\end{array}$ & $\begin{array}{c}\text { Aspect } \\
\text { ratio }\end{array}$ & $\begin{array}{c}\text { Mean/mode } \\
\text { radius }\end{array}$ \\
\hline Gaussian, $\sigma=24 \mathrm{~nm}$ & cylinder & 1.0 & $56.2 \mathrm{~nm}$ \\
Gaussian, $\sigma=24 \mathrm{~nm}$ & spheroid & 1.0 & $55.6 \mathrm{~nm}$ \\
Log-normal, $\sigma=1.4$ & spheroid & 1.0 & $50.7 \mathrm{~nm}$ \\
Gaussian, $\sigma=24 \mathrm{~nm}$ & cylinder & 0.2 & $78.4 \mathrm{~nm}$ \\
Gaussian, $\sigma=24 \mathrm{~nm}$ & cylinder & 0.5 & $58.1 \mathrm{~nm}$ \\
Gaussian, $\sigma=24 \mathrm{~nm}$ & cylinder & 2.0 & $50.5 \mathrm{~nm}$ \\
Gaussian, $\sigma=24 \mathrm{~nm}$ & cylinder & 5.0 & $45.5 \mathrm{~nm}$ \\
\hline
\end{tabular}

years $2003-2007$ is $74.3 \mathrm{~nm}$, i.e., significantly larger than for $24 \mathrm{~nm}$ width. We note, that the difference in mean radii is certainly not identical to the difference in width if the latter is changed.

High resolution images of NLCs taken from the ground or with the CIPS (Cloud Imaging and Particle Size) experiment (Rusch et al., 2009) on the AIM (Aeronomy of Ice in the Mesosphere) satellite (Russell et al., 2009) show a remarkable fine structure in the NLC brightness field on spatial scales as low as several kilometers, and temporal scales of minutes. While the time required to form a $60 \mathrm{~nm}$ NLC particle is typically on the order of tens of hours (e.g., Berger and von Zahn, 2002), it only takes several tens of minutes to sublimate the large particles, if the temperature is perturbed (e.g., Rapp et al., 2002). Therefore, we must expect that the strong small scale variations in NLC brightness are also associated with small scale variations in the local NLC particle size distribution, and the mean radius in particular. SCIAMACHY and the ALOMAR RMR LIDAR sample air volumes of very different sizes. As mentioned already above, the horizontal extent of the air volume sampled by SCIAMACHY is about $1000 \mathrm{~km} \times 400 \mathrm{~km}$, whereas the instantaneous field of view of the LIDAR at NLC altitude is about $20 \mathrm{~m} \times 30 \mathrm{~km}$. Therefore, a validation of the SCIAMACHY NLC particle size retrievals using the LIDAR observations may not be possible in a strict sense. However, the comparison of averaged particle sizes (in the spatial sense for SCIAMACHY or other satellite instruments, and in the temporal sense for the LIDAR) is still valuable and provides insight in the quality of the satellite retrievals of NLC particle size.

\section{Conclusions}

NLC particle sizes retrieved from SCIAMACHY observations of limb-scattered solar radiation are compared to spatially co-located ground-based NLC size measurements made with the ALOMAR RMR LIDAR. Because of the much larger horizontal extension of the air volume sampled 
by SCIAMACHY the width of particle size distribution assumed for the SCIAMACHY retrievals was adjusted to account for the variability of the local NLC particle size distribution. The poorer vertical resolution of SCIAMACHY was taken into account by determining weighted vertical mean LIDAR NLC particle sizes. Once these aspects are considered, we obtain very good agreement between the averaged SCIAMACHY and LIDAR radii with a mean difference of only about $2 \mathrm{~nm}$. Considering the differences in spatial (i.e., horizontal and vertical) resolution between different instruments will be crucial in future comparisons of NLC particle size observations.

Acknowledgements. We gratefully acknowledge the support of the ALOMAR staff and by a huge number of voluntary LIDAR operators. This work received research funding from the European Community's 6th Framework Programme under the project "ALOMAR eARI" (RITA-CT-2003-506208). The project was also supported by the Deutsche Forschungsgemeinschaft under the CAWSES SPP Grant LU 1174/3-1 (SOLEIL). The analysis of SCIAMACHY data was supported by the German Ministry of Education and Research (BMBF), the German Aerospace Center (DLR) and the University of Bremen (Project ICAPS). SCIAMACHY is jointly funded by Germany, The Netherlands, and Belgium.

Edited by: A. Lambert

\section{References}

Bailey, S. M., Thomas, G. E., Rusch, D. W., Merkel, A. W., Jeppesen, C., Carstens, J. N., Randall, C. E., McClintock, W. E., and Russell III, J. M.: Phase Functions of Polar Mesospheric Cloud Ice as Observed by the CIPS Instrument on the AIM Satellite, J. Atmos. Sol.-Terr. Phys., 71(3-4), 373-380, doi:10.1016/j.jastp.2008.09.039, 2009.

Baumgarten, G., Fricke, K. H., and von Cossart, G.: Investigation of the shape of noctilucent cloud particles by polarization lidar technique, Geophys. Res. Lett., 29(13), 1630, doi:10.1029/2001GL013877, 2002.

Baumgarten, G., Fiedler, J., and von Cossart, G.: The size of noctilucent cloud particles above Alomar $(69 \mathrm{~N}, 16 \mathrm{E})$ : optical modeling and method description, Adv. Space Res., 40(6), 772-784, doi:10.1016/j.asr.2007.01.018, 2007.

Baumgarten, G. and Fiedler, J.: Vertical structure of particle properties and water content in noctilucent clouds, Geophys. Res. Lett., 35, L10811, doi:10.1029/2007GL033084, 2008.

Baumgarten, G., Fiedler, J., Lübken, F.-J., and von Cossart, G.: Particle properties and water content of noctilucent clouds and their interannual variation, J. Geophys. Res., 113, D06203, doi:10.1029/2007JD008884, 2008.

Baumgarten, G., Fiedler, J., Fricke, K.-H., Gerding, M., Hervig, M., Hoffmann, P., Müller, N., Pautet, P.-D., Rapp, M., Robert, C., Rusch, D., von Savigny, C., and Singer, W.: The noctilucent cloud (NLC) display during the ECOMA/MASS sounding rocket flights on August 3, 2007: Morphology on global to local scales,
Ann. Geophys., 27, 953-965, 2009,

http://www.ann-geophys.net/27/953/2009/.

Berger, U. and von Zahn, U.: Icy particles in the summer mesopause region: Three-dimensional modeling of their environment and two-dimensional modeling of their transport, J. Geophys. Res., 107(A11), p. 1366, doi:10.1029/2001JA000316, 2002.

Bovensmann, H., Burrows, J. P., Buchwitz, M., Frerick, J., Noël, S., Rozanov, V. V., Chance, K. V., and Goede, A. P. H.: SCIAMACHY: Mission objectives and measurement modes, J. Atmos. Sci., 56(2), 127-150, 1999.

Carbary, J. F., Morrison, D., and Romick, G. J.: Evidence for bimodal particle distribution from the spectra of polar mesospheric clouds, Geophys. Res. Lett, 31, L13108, doi:10.1029/2004GL020101, 2004.

Debrestian, D., Lumpe, J., Shettle, E., Bevilacqua, R., Olivero, J., Hornstein, J., Glaccum, W., Rusch, D., Randall, C., Fromm, M., An analysis of POAM II solar occultation observations of polar mesospheric clouds in the southern hemisphere, J. Geophys. Res., 102(D2), 1971-1981, 1997.

DeLand, M. T., Shettle, E. P., Thomas, G. E., and Olivero, J. J.: Spectral measurements of PMCs from SBUV/2 instruments, J. Atmos. Sol.-Terr. Phys., 68(1), 65-77, doi:10.1016/j.jastp.2005.08.006, 2005.

Eremenko M. N., Petelina, S. V., Zasetsky, A. Y., Karlsson, B., Rinsland, C. P., Llewellyn, E. J., and Sloan, J. J.: Shape and composition of PMC particles derived from satellite remote sensing measurements, Geophys. Res. Lett., 32, L16S06, doi:10.1029/2005GL023013, 2005.

Fiedler, J., Baumgarten, G., and von Cossart, G.: Mean diurnal variation of noctilucent clouds during 7 years of lidar observations at ALOMAR, Ann. Geophys., 23, 1175-1181, 2005, http://www.ann-geophys.net/23/1175/2005/.

Gumbel, J. and Witt, G.: Rocket-borne photometry of NLC particle populations, Adv. Space Res., 28(7), 1053-1058, 2001.

Hervig, M., Thompson, R., McHugh, M., Gordley, L., Russell III, J., and Summers, M.: First Confirmation that Water Ice is the Primary Component of Polar Mesospheric Clouds, Geophys. Res. Lett., 28(6), 971-974, 2001.

Hervig, M. E., Gordley, L. L., Russell III, J. M., and Bailey, S. M.: SOFIE PMC observations during the northern summer of 2007, J. Atmos. Sol. Terr. Phys., 71(3-4), 331 - 339, doi:10.1016/j.jastp.2008.08.010, 2009.

Karlsson, B. and Rapp, M.: Latitudinal Dependence of Noctilucent Cloud Growth, Geophys. Res. Lett., 33, L11812, doi:10.1029/2006GL025805, 2006.

Lumpe J. D., Alfred, J. M., Shettle, E. P., and Bevilacqua, R. M.: Ten years of Southern Hemisphere polar mesospheric cloud observations from the Polar Ozone and Aerosol Measurement instruments, J. Geophys. Res., 113, D04205, doi:10.1029/2007JD009158, 2008.

Megner, L., Gumbel, J., Rapp, M., and Siskind, D. E.: Reduced meteoric smoke particle density at the summer pole - Implications for mesospheric ice particle nucleation, Adv. Space Res., 41, 41-49, doi:10.1016/j.asr.2007.09.006, 2008.

Mishchenko, M. I. and Travis, L. D.: Capabilities and limitations of a current FORTRAN implementation of the T-matrix method for randomly oriented, rotationally symmetric scatterers, J. Quant. Spectrosc. Radiat. Tranfer, 60, 309-324, doi:10.1016/S00224073(98)00008-9, 1998. 
Rapp, M., Lübken, F.-J., Müllemann, A., Thomas, G. E., and Jensen, E. J.: Small-scale temperature variations in the vicinity of NLC: Experimental and model results, J. Geophys. Res., 107(D19), 4392, doi:10.1029/2001JD001241, 2002.

Robert, C. E., von Savigny, C., Burrows, J. P., and Baumgarten, G.: Climatology of noctilucent cloud radii and occurrence frequency using SCIAMACHY, J. Atmos. Sol.-Terr. Phys., 71(3-4), 408423, doi:10.1016/j.jastp.2008.10.015, 2009.

Rusch, D. W., Thomas, G. E., and Jensen, E. J.: Particle size distributions in polar mesospheric clouds derived from Solar Mesosphere Explorer measurements, J. Geophys. Res., 96, 1293312939, 1991.

Rusch, D. W., Bailey, S. M., Thomas, G. E., and Merkel, A. W.: Seasonal Variation of PMC Particle Size from SNOE UV Measurements for the Northern 2000 and Southern 2000/2001 Seasons, J. Atmos. Sol.-Terr. Phys., 70(1), 71-88, doi:10.1016/j.jastp.2007.10.006, 2008.

Rusch, D. W., Thomas, G. E., McClintock, W., Merkel, A. W., Bailey, S. M., Russell III, J. M., Randall, C. E., Jeppesen, C., and Callan, M.: The Cloud Imaging and Particle Size Experiment on the Aeronomy of Ice in the Mesosphere Mission: Cloud Morphology for the Northern 2007 season, J. Atmos. Sol.-Terr. Phys., 71(3-4), 356-364, doi:10.1016/j.jastp.2008.11.005, 2009.
Russell, J. M. III, Bailey, S. M., Gordley, L. L., Rusch, D. W., Horányi, M., Hervig, M. E., Thomas, G. E., Randall, C. E., Siskind, D. E., Stevens, M. H., Summers, M. E., Taylor, M. J., Englert, C. R., Espy, P. J., McClintock, W. E., and Merkel, A. W.: The aeronomy of ice in the mesosphere (AIM) mission: Overview and early science results, J. Atmos. Sol.-Terr. Phys., 71(3-4), 289-299, doi:10.1016/j.jastp.2008.08.011, 2009.

Thomas, G. E. and McKay, C. P.: On the mean particle size and water content of polar mesospheric clouds, Planet. Space Sci., 33(10), 1209-1224, 1985.

von Cossart, G., Fiedler J., and von Zahn, U., Size distributions of NLC particles as determined from 3-color observations of NLC by ground-based lidar, Geophys. Res. Lett., 26, 1513-1516, 1999.

von Savigny, C., and Burrows, J. P., Latitudinal variation of NLC particle radii derived from northern hemisphere SCIAMACHY/Envisat limb measurements, Adv. Space Res., 40, 765771, doi:10.1016/j.asr.2006.12.032, 2007.

von Savigny, C., Rapp, M., and Burrows, J. P., UV limbscatter spectra of noctilucent clouds consistent with mono-modal particle size distribution, Geophys. Res. Lett., 34, L07802, doi:10.1029/2006GL028846, 2007. 